\title{
Treatment of low-level As contaminated excavated soils using ZVI amendment followed by magnetic retrieval
}

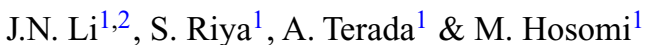 \\ ${ }^{1}$ Department of Chemical Engineering, Tokyo University of Agriculture and Technology, Tokyo, Japan \\ ${ }^{2}$ Research Fellow of Japan Society for the Promotion of Science, Tokyo, Japan
}

\begin{abstract}
This study investigates the remediation of low-level As contaminated excavated soils from construction projects by ZVI amendment followed by magnetic retrieval. A case study was conducted with an alkaline excavated soil (total As only $7.5 \mathrm{mg} \mathrm{kg}^{-1}$ ). The remediation efficiency was assessed using sequential leaching tests. The results showed ZVI amendment ( $1 \% \mathrm{ZVI}$ and $0.5 \mathrm{~mL} \mathrm{~kg}^{-1} \mathrm{H}_{2} \mathrm{SO}_{4}$ of soil) followed by magnetic retrieval could significantly decrease water-leachable As (from $33 \mu \mathrm{g} \mathrm{L}^{-1}$ to $<3 \mu \mathrm{g} \mathrm{L}^{-1}$ ), also the potential leachability of As in this excavated soil. These initial results indicate that this treatment could be developed for the efficient remediation of low-level As contaminated excavated soils.
\end{abstract}

\section{INTRODUCTION}

In Japan, excavated soils with low-level As obtained from construction projects during city development have been of great concern because in many cases the water-leachable As is higher than the environment standard (Soil Leachate Standard in Soil Contamination Countermeasures Law of Japan, $\left.10 \mu \mathrm{g} \mathrm{L}^{-1}\right)(\mathrm{Li}$ et al., 2016, 2017). Now water washing is usually used for the remediation of As-contaminated soils, after which the large soil grains can be reused immediately while the fine soil grains contain high levels of As need to be further treated. After washing, the fine soil grains are more like "sludge" and they are usually treated in disposal sites, which will greatly increase the transportation cost and the load of disposal sites. Hence, the development a cost-effective disposal system to treat low-level As-contaminated excavated soils is urgently needed. The objective of this study was to probe the effectiveness of the zero valent iron (ZVI) amendment followed by magnetic retrieval for remediation of low-level As contaminated excavated soils.

\section{MATERIALS AND METHODS}

\subsection{Soil sample and ZVI product}

The excavated soil was obtained from one construction project in Tokyo, Japan. The sample was air-dried, crushed and sieved through a 2-mm opening mesh. Soil moisture content was $32.5 \%$; soil pH was 9.0 (soil to water ratio; $1: 10$ ); total As was $7.5 \pm 0.13 \mathrm{mg} \mathrm{kg}^{-1}$. The ZVI product was obtained from DOWA ECOSYSTEM, Japan. The Fe content was $940 \pm 7.4 \mathrm{~g} \mathrm{~kg}^{-1}$; the As content was $13.4 \pm 0.5 \mathrm{mg} \mathrm{kg}^{-1}$.

\subsection{Soil treatment}

Before amendment experiment, water content of the soil was adjusted to $15 \%$ using deionized water. This
Table 1. Different soil treatments.

\begin{tabular}{ll}
\hline Test & Description \\
\hline T1 & Original soil (Control 1) \\
T2 & No ZVI; No $\mathrm{H}_{2} \mathrm{SO}_{4}($ Control 2) \\
T3 & No ZVI; Add $\mathrm{H}_{2} \mathrm{SO}_{4}\left(0.5 \mathrm{~mL} \mathrm{~kg}^{-1}\right.$ of soil $)$ \\
T4 & Add ZVI $\left(10 \mathrm{~g} \mathrm{~kg}^{-1}\right) ; \mathrm{No} \mathrm{H}_{2} \mathrm{SO}_{4}$ \\
T5 & Add ZVI $\left(10 \mathrm{~g} \mathrm{~kg}^{-1}\right) ; \mathrm{Add} \mathrm{H}_{2} \mathrm{SO}_{4}\left(0.5 \mathrm{~mL} \mathrm{~kg}^{-1}\right)$ \\
\hline
\end{tabular}

ZVI and $\mathrm{H}_{2} \mathrm{SO}_{4}$ were added on the basis of dry mass of soil.

water content is very low and avoids producing sludge during treatment process. The detailed information about different soil treatments was shown in Table 1. In all treatments, the samples were agitated intensely for $15 \mathrm{~min}$ and then air-dried at room temperature. For magnetic retrieval, two steps were conducted: (1) a rectangular magnet was held in contact with the treated soils' surfaces and moved horizontally back and forth until no solids could be pulled out of the soils. The remaining soils were considered as non-magnetic (NMS); (2) the mixtures obtained at previous step were further magnetically-separated to retrieve ZVI powders only (post-test ZVI); and the remaining soils after this step were considered as weakly-magnetic (WMS). The As and other elements in different parts were digested using a strong acid $\left(\mathrm{HClO}_{4}-\mathrm{HNO}_{3}-\mathrm{HF}\right)$ digestion method.

\subsection{Sequential leaching tests (SLT)}

The parameters of each step of SLT were generally in accord with the standard leaching test in Japan. $3 \mathrm{~g}$ of sample was mixed with $30 \mathrm{~mL}$ deionized water in a $50 \mathrm{~mL}$ polypropylene centrifuge tube. The tubes were shaken using a lateral-reciprocating shaker at $200 \mathrm{rpm}$ for $6 \mathrm{~h}$ at room temperature, after which the $\mathrm{pH}$ values of the suspensions were measured immediately. The suspensions were then centrifuged at about $6000 \mathrm{rpm}$ 


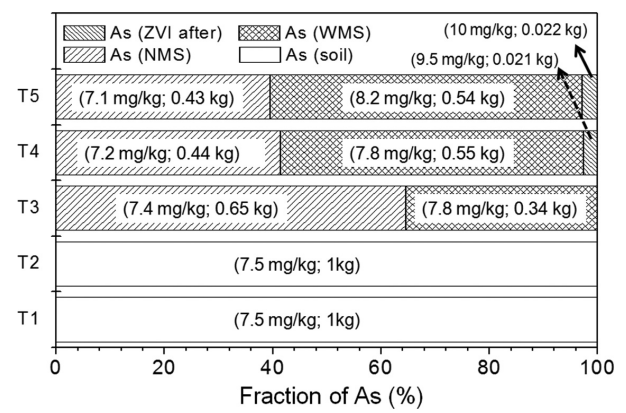

Figure 1. Fractions of As in different separated soils and ZVI.

$(4700 \mathrm{~g})$ for $15 \mathrm{~min}$, followed by filtration through $0.45 \mu \mathrm{m}$ membrane filters. The residual soils remaining in the tubes were stored at $4{ }^{\circ} \mathrm{C}$ overnight and were re-suspended in fresh deionized water the next day for the next leaching step. This procedure was repeated 5 times in total.

\section{RESULTS AND DISCUSSION}

\subsection{Distributions of As before and after treatment}

The distributions of As in soils and ZVI are shown in Figure 1. The As concentrations in WMS of T3, T4 and T5 were higher than those in NWS. Similarly, the $\mathrm{Fe}, \mathrm{Mn}, \mathrm{Cr}, \mathrm{Cu}$ and $\mathrm{Zn}$ concentrations in WMS were higher than those in NWS (data not shown). This can be attributed to the separation of magnetic minerals in WMS that are often associated with heavy metal(loid)s. As shown in Figure 1, the As concentrations in post-test ZVI (T4: $10 \mathrm{mg} \mathrm{kg}^{-1}$; T5: $9.5 \mathrm{mg} \mathrm{kg}^{-1}$ ) were lower than that in pre-test ZVI; but the removal of As from soils was also confirmed due to the mass of post-test ZVI increased more than two times. Nevertheless, the removal efficiency of As by ZVI was not high (lower than $0.6 \%$ ).

\subsection{Arsenic leaching concentrations}

The As concentrations at the first step of $\mathrm{T} 1$ $\left(33 \mu \mathrm{g} \mathrm{L}^{-1}\right)$ and $\mathrm{T} 2\left(36 \mu \mathrm{g} \mathrm{L}^{-1}\right)$ were all higher than the standard $10 \mu \mathrm{gL}^{-1}$, indicating that this excavated soil was considered as slightly contaminated and needed to be remediated. When only the ZVI was used (T4), the As leaching concentrations decreased but still more than $20 \mu \mathrm{g} \mathrm{L}^{-1}$ in the leachate. When only acid was added (T3), the As concentrations decreased more than those in T3 but still slightly higher than the standard. Only when both the ZVI and acid was used, the As concentrations at the first step of T5 were decreased a lot and lower than the standard, indicating this treatment can efficiently treat this excavated soil. As described in previous section, it seems that the removal of As by ZVI was not the key factor decreasing the As leaching at the first step of SLT. The slight $\mathrm{pH}$ decrease due to the addition of acid in T3 (mean: 8.1) and T5 (mean: 8.0) contributed the As leaching decrease

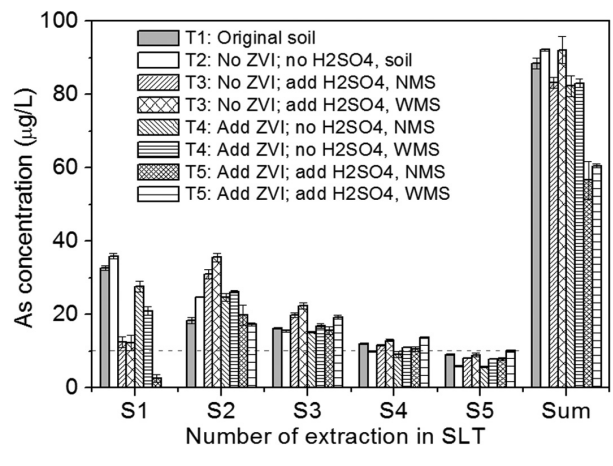

Figure 2. Leaching of As in sequential leaching tests.

because the As mobility was quite limited in the circumneutral $\mathrm{pH}$ (6-8) (Tabelin et al., 2014). The comparison between T3 and T5 also confirmed the ZVI addition contributed to the As leaching decrease after treatment.

Interestingly, the As release during SLT could last for a long period. For soils in T3 and T5, the As concentrations increased at the second step and then decreased at later steps. It required about 5 times until the As concentrations in the leachates lower than the standard $10 \mu \mathrm{g} \mathrm{L}^{-1}$. Figure 2 also shows that the T5 treatment significantly reduced the potential leachibility of As in soils (sum of released As in five-step SLT).

\section{CONCLUSIONS}

This study suggests that ZVI amendment followed by magnetic retrieval is technologically feasible to treat low-level As contaminated excavated soils and reveals promising perspective for its practical application.

\section{ACKNOWLEDGEMENTS}

This research was financially supported by an Environmental Research and Technology Development Fund (5-1606) from the Ministry of the Environment, Japan and a Grant-in-Aid for Scientific Research (No. 17J07673) from the JSPS.

\section{REFERENCES}

Li, J.N., Kosugi, T., Riya, S., Hashimoto, Y., Hou, H., Terada, A. \& Hosomi, M. 2017. Use of batch leaching tests to quantify arsenic release from excavated urban soils with relatively low levels of arsenic. J. Soil. Sediment. 17(8): 2136-2143.

Li, J.N., Kosugi, T., Riya, S., Hashimoto, Y., Hou, H., Terada, A. \& Hosomi, M. 2018. Pollution potential leaching index as a tool to assess water leaching risk of arsenic in excavated urban soils. Ecotoxicol. Environ. Saf. 147: $72-79$.

Tabelin, C.B., Hashimoto, A., Igarashi, T. \& Yoneda, T. 2014. Leaching of boron, arsenic and selenium from sedimentary rocks: II. pH dependence, speciation and mechanisms of release. Sci. Total Environ. 473: 244-253. 